\title{
A case-control study on risk predictors associated with periodontitis in systemically healthy patients; a Regression Analysis
}

\section{DR. HINA MAHMOOD}

Islamabad Medical and Dental College

DR. SEHAR NAEEM ( $\square$ sehar.naeem@iideas.edu.pk)

Islamabad Medical and Dental College

DR. UZMA SAEED

Islamabad Medical and Dental College

DR. BATOOL ZARA

Foundation University Medical College

\section{Research Article}

Keywords: Periodontitis, Education, Dental care, Case-control study

Posted Date: July 14th, 2021

DOI: https://doi.org/10.21203/rs.3.rs-476561/v2

License: (a) (i) This work is licensed under a Creative Commons Attribution 4.0 International License. Read Full License

Version of Record: A version of this preprint was published at Journal of Pharmaceutical Research International on December 20th, 2021. See the published version at https://doi.org/10.9734/jpri/2021/v33i60A34526. 


\section{A case-control study on risk predictors associated with periodontitis in systemically healthy patients; a Regression Analysis}

DR. HINA MAHMOOD ${ }^{1}$, DR. SEHAR NAEEM ${ }^{2}$, DR. UZMA SAEED ${ }^{3}$, AYESHA USMANI ${ }^{4}$, DR. BATOOL ZARA ${ }^{5}$

${ }^{1}$ Associate Professor and Head of periodontology department, Islamabad Medical \& Dental College (Dental section), Barahkahu, Islamabad, Pakistan

${ }^{2}$ (Corresponding Author) Post Graduate Trainee periodontology department, Islamabad Medical \& Dental College (Dental section), Barahkahu, Islamabad, Pakistan

Email address: sehar_n20@hotmail.com

Contact \# 0333-0226614

${ }^{3}$ Post graduate Trainee periodontology department, Islamabad Medical \& Dental College (Dental section), Barahkahu, Islamabad, Pakistan

${ }^{4}$ Biostatistician, Islamabad Medical \& Dental College (Dental Section), Barahkahu, Islamabad, Pakistan

${ }^{5}$ Assistant Professor and Head of periodontology department, Foundation University Medical College, Islamabad, Pakistan

Data will be available on reviewer's request 


\section{ABSTRACT:}

OBJECTIVE: This case-control study was conducted to analyze the association of periodontitis with risk indicators i.e. age, gender, education status, brushing habits and past dental visits in systemically healthy patients.

METHODS: The study included total of 1097 systemically healthy, non-tobacco using patients with age $\geq 18$ years that reported to periodontology department from year 2018 . The demographic details and dental care pattern of the patients were extracted from the records of periodontology department, and their frequencies were formulated. The association of five study variables i.e. age, gender, education status, brushing habits and past dental visits was assessed using forward step-wise logistic regression analysis.

RESULTS: Total of $471(42.9 \%)$ patients were diagnosed with periodontitis. Higher frequency of periodontitis was observed in patients who were male and $\geq 50$ years of age. Regression analysis showed that the subjects with $<50$ years of age, $\geq 12$ years of education, regular brushing habits and regular past dental visits had greater odds of being safe from periodontitis.

CONCLUSION: Since the population chosen for this research was systemically healthy, non-tobacco using individuals, a high prevalence (42.9\%) of periodontitis was observed indicating the need to analyze the factors other than systemic conditions contributing in prevalence of periodontitis. Furthermore, a positive association between study variables and periodontitis was observed in this research, which will help the clinicians in prediction of periodontitis in systemically healthy, non-tobacco using individuals.

KEYWORDS: Periodontitis, Education, Dental care, Case-control study 


\section{INTRODUCTION:}

Periodontitis is a disease of the supporting tissues of the teeth, characterized as irreversible polymicrobial breakdown of host homeostasis resulting in a progressive destruction of periodontium supporting the teeth. ${ }^{1}$

The prevalence of periodontal diseases has been reported in many studies worldwide which vary depending upon the criteria being used and the diversity in population being studied. ${ }^{2}$ Data from epidemiological studies reported in 2016 reveal that Periodontitis is the sixth most prevalent chronic condition in the world. ${ }^{3}$ As reported by Marcenes W et al. in 2013, globally about $11 \%$ of individuals, are suffering with severe type of periodontitis. ${ }^{4}$ In Pakistan, data from 2003-2012 reported that $18 \%$ of the population suffers from periodontitis out of which $31 \%$ suffered from advanced periodontitis. ${ }^{5}$

Periodontitis is a chronic condition influenced by numerous systemic, local and environmental factors. Adverse effects of factors like, tobacco, diabetes, and stress on periodontal health have been reported widely all around the world and their link is well established. ${ }^{6}$ There is also fair evidence in literature indicating that lower education level results in inadequate oral health knowledge, insufficient dental preventive behaviors, and less usage of oral health services in general population. ${ }^{7} \mathrm{~A}$ higher prevalence of periodontitis among subjects with low education level and increased age has also been reported. ${ }^{8}$ Inadequate oral hygiene practice is a significant factor that plays a role on plaque accumulation and development of periodontal disease. ${ }^{9}$ Regular dental visits are also considered important for the success in prevention and control of periodontitis, therefore maintaining a functional dentition. ${ }^{10}$ The literature also enlighten the importance of age, gender, education status, brushing habits and past dental visits in prevention and control of periodontitis, however none of the researches have been conducted in systemically healthy individuals solely. $6,7,8,9,10$ Although the relationship between periodontitis and the factors under consideration for present study have already been established worldwide, but their role in influencing incidence in systemically healthy patients is still obscure. Considering that these factors alone play a pivotal role in periodontal disease, they have been masked in previous studies conducted. This study focuses on prevalence of periodontitis in nontobacco using, systemically healthy patients and includes the risk indicators which may be 
linked with this irreversible disease so that prediction and prevention of periodontitis is possible in these patients as well.

\section{METHODOLOGY:}

This case-control study was conducted in periodontology department of Islamabad Medical and Dental College (dental section). After approval from institutional review board, record files of 4,490 patients were retrieved from periodontology department for the year 2018 from $1^{\text {st }}$ January to $31^{\text {st }}$ December. The data were present in the form of standard questionnaire based history sheets along with sheets elaborating intra-oral and extra-oral clinical findings, radiographic findings as well as full mouth periodontal charting sheets including measurements of 6-point periodontal pocket depth, gingival recession, furcation involvement, mobility and attachment level. From the records patient's selection was done according to the inclusion criteria as shown in flow chart (fig 1). Data were extracted from the records by exploring dental history, education status, oral hygiene practice and past dental visits.

\section{Fig 1: Flow chart of patient selection.}

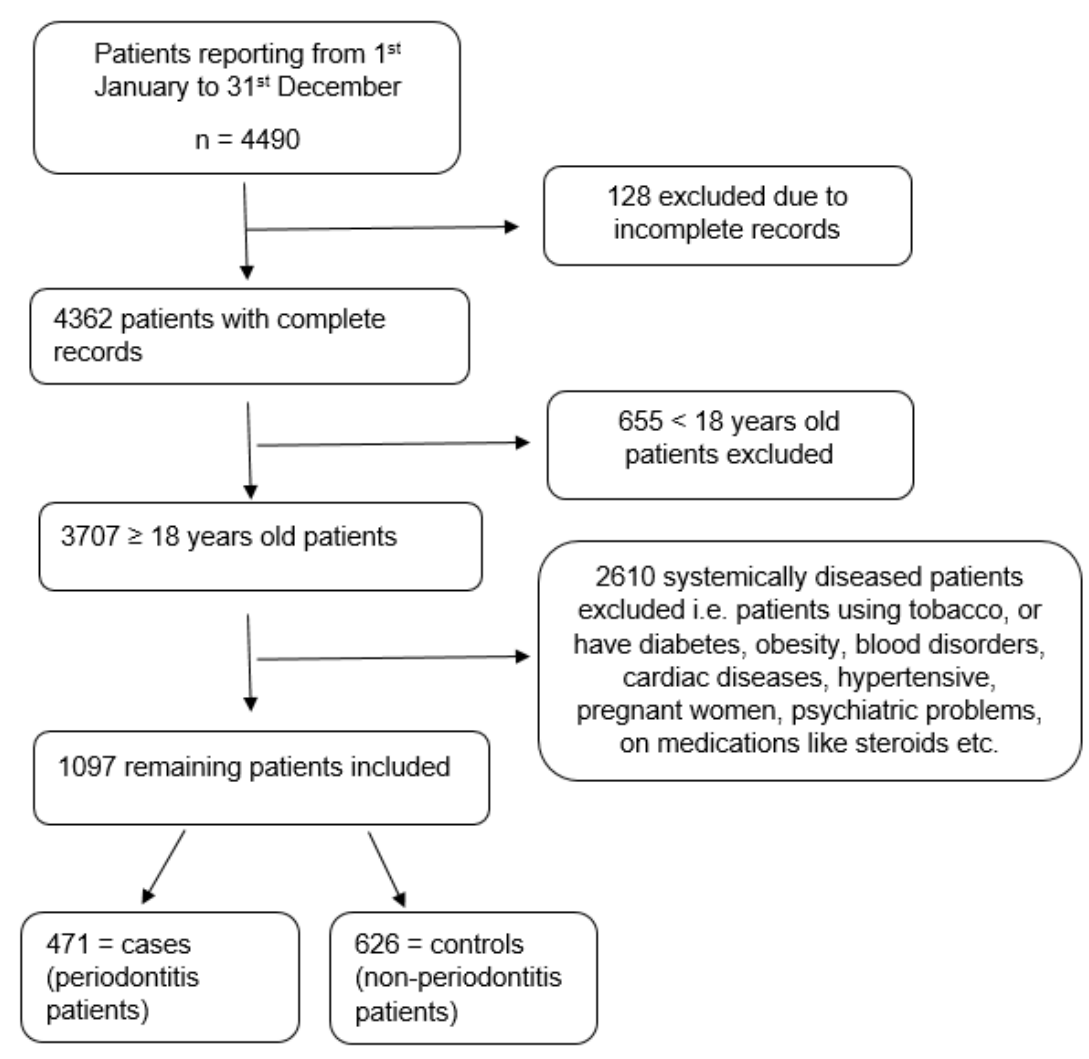


Patients diagnosed with periodontitis were chosen as case and the non-periodontitis were considered as controls. The past medical and dental history, periodontal examination records and radiographic findings were evaluated, and patients were diagnosed with periodontitis accordingly on the criteria of periodontal classification proposed in $2017 .{ }^{11}$ The five study variables (exposures) chosen were age, gender education status, brushing habits and past dental history. Age of the patients and education status were divided into two groups $(18-49 \text { years and } \geq 50)^{12}$, (years of education $<12$ and years of education $\left.\geq 12\right)^{9}$ respectively. Brushing habits of the patients was divided into three groups (regular, irregular and never brushers). ${ }^{13}$ Past dental visits of patients were divided into three groups i.e. those who visit once in a year (regular attendee), those who visit only when they encounter a dental problem (irregular dental attendee) and those who never visited a dentist before. ${ }^{14}$

\section{STATISTICAL ASSESSMENT:}

The data were entered in the statistical package for social sciences (SPSS) software version 22. The periodontal diagnosis of the patients was established, and the frequencies were formulated. Sub analysis of patients suffering from periodontitis was done by using crosstabulation to formulate percentages of periodontitis within individual variable. The effects of study variables on periodontitis were studied by applying forward step-wise logistic regression analysis. The dependent variable (outcome) was periodontitis with the reference category, absence of periodontitis. The independent variables (predictors) were age, gender, patient education level, brushing habits and past dental visits the corresponding reference categories as 50-80, female, $<12$, never brushed, and never visited. HosmerLameshow goodness of fit test was applied to determine whether the model adequately describes the data. Wald's statistics and odd's ratio (with 95\% confidence interval limit) were used to assess the significance and contribution of individual variables. A p-value of $<0.05$ was considered statistically significant for all the variables.

\section{RESULTS:}

This retrospective case-control study included 1097 patients. Socio-demographic details with dental care pattern of the total patients are given in table 1 which shows that more than half $(86.1 \%)$ of the patients were $18-49$ years old females. Furthermore, more than half of the patients had $<12$ years of education $(66.3 \%)$, brushed regularly $(78.9 \%)$ and visited the dental clinic for the first time (45.1\%). 
$\underline{\text { TABLE 1. Demographic data and dental care pattern of patients }}$

\begin{tabular}{|c|c|c|c|}
\hline VARIABLES & FREQUENCIES IN TOTAL & FREQUENCIES IN CASES & FREQUENCIES IN CONTROLS \\
\hline$\nabla$ & $\nabla$ & $\nabla$ & \\
\hline & $n=1097$ & $n=471$ & $n=626$ \\
\hline \multicolumn{4}{|l|}{ AGE } \\
\hline $18-49$ & 944 & 363 & 581 \\
\hline$\geq 50$ & 153 & 108 & 45 \\
\hline \multicolumn{4}{|l|}{ GENDER } \\
\hline Male & 468 & 218 & 250 \\
\hline Female & 629 & 253 & 376 \\
\hline \multicolumn{4}{|l|}{ EDUCATION } \\
\hline $\begin{array}{c}<12 \text { years of } \\
\text { education }\end{array}$ & 727 & 357 & 370 \\
\hline $\begin{array}{l}\geq 12 \text { years of } \\
\text { education }\end{array}$ & 370 & 114 & 256 \\
\hline \multicolumn{4}{|l|}{$\begin{array}{l}\text { BRUSHING } \\
\text { HABITS }\end{array}$} \\
\hline $\begin{array}{l}\text { Never brushed } \\
\text { before Irregular }\end{array}$ & 127 & 91 & 36 \\
\hline \multirow[t]{2}{*}{ Regular } & 104 & 75 & 29 \\
\hline & 866 & 305 & 561 \\
\hline \multicolumn{4}{|l|}{$\begin{array}{c}\text { PAST } \\
\text { DENTAL } \\
\text { VISITS }\end{array}$} \\
\hline $\begin{array}{l}\text { Never visited } \\
\text { before }\end{array}$ & 495 & 212 & 283 \\
\hline Irregular & 468 & 239 & 229 \\
\hline Regular & 134 & 20 & 114 \\
\hline
\end{tabular}

Forward step-wise logistic regression analysis was used for the prediction of periodontitis in systemically healthy patients. The classification table indicates, how well the model predicts that periodontitis is absent or present in a patient (table 2). The model correctly classifies 224 patients who had periodontitis but misclassified 247 (it correctly classified $47.6 \%$ of the patients). The model also correctly classified 537 patients who had no periodontitis but misclassified 89 (it correctly classified $85.8 \%$ of the patients). The overall accuracy of the classification is $69.4 \%(224+537 / 1097)$ after the inclusion of all predictors in the model. It implies that the model is in fact correct about two out of three times (table 2). 
TABLE 2. Classification table after inclusion of predictors

\begin{tabular}{|c|c|c|c|c|c|}
\hline \multirow{3}{*}{\multicolumn{2}{|c|}{ Observed }} & \multicolumn{3}{|c|}{ Predicted } & \multirow{3}{*}{$\begin{array}{c}\text { Percenta } \\
\text { ge }\end{array}$} \\
\hline & & \multicolumn{2}{|c|}{ Periodontitis } & \multirow{2}{*}{ Total } & \\
\hline & & Present & Absent & & \\
\hline \multirow{2}{*}{$\begin{array}{l}\text { Periodon } \\
\text { titis }\end{array}$} & Prese & 224 & 247 & 471 & $47.60 \%$ \\
\hline & Absent & 89 & 537 & 626 & $85.80 \%$ \\
\hline \multicolumn{2}{|c|}{ Overall percentage } & & & 1097 & $69.40 \%$ \\
\hline
\end{tabular}

Hosmer-Lameshow goodness of fit test indicates that model adequately fits the data ( $\mathrm{p}$ value 0.804$)$. Wald's statistics showed significant results for all the predictors ( ${ }^{*} p$ value $<$ 0.05) except irregular dental visits and irregular brushing habits (table 3). It implies that age, gender, education, regular brushing, and regular dental visits making significant contribution to the prediction of periodontitis. The odd's ratio $\left(\mathrm{e}^{\mathrm{b}}\right)$, after adjusting for the levels of other predictors, reported the strength and direction of association between the predictors and the outcome. The strongest association was seen between periodontitis and brushing habits of the patients as the patients who brush their teeth once or twice daily (regular brushers) have $3.4(\mathrm{OR}>1)$ times the odds of not getting periodontitis (absence) than those who don't brush their teeth. Similarly, the odds of absence of periodontitis for regular visitors are 3.21 times as great as for the reference group (never visited). However, odd's ratio $<1$ was found for irregular dental visits, irregular brushing habits and gender indicating that these patients correspond with lower odds of not suffering from periodontitis as compared to their reference groups. For gender $(\mathrm{OR}=0.74)$, the odds of absence of periodontitis are $26 \%$ lesser for males as compared to the females (table 3).

TABLE 3: Forward stepwise binary logistics regression analysis using periodontitis as dependent variable

\begin{tabular}{|c|c|c|c|}
\hline Independent Variables $\square$ & Regression coefficient (b) $\nabla$ & Wald's statistics $\square$ Significance (p-value) & Odd's Ratio (eb) $=95 \%$ C.I for Odd's ratio \\
\hline Age (18-49) & 1.064 & $26.8120 .000^{*}$ & $2.91 .9-4.3$ \\
\hline Gender (male) & -0.3 & $4.8160 .028^{*}$ & $0.740 .56-0.96$ \\
\hline Education status ( $\geq 12$ year & 0.43 & $8.3190 .004^{*}$ & $1.541 .15-2.06$ \\
\hline Brushing habits (irregular) & -0.049 & 0.026 & $0.950 .52-1.72$ \\
\hline Brushing habits (regular) & 1.216 & $30.9770 .000^{*}$ & $3.372 .19-5.17$ \\
\hline Pastdental visits (irregular & -0.229 & 2.66 & $0.80 .60-1.04$ \\
\hline Pastdental visits (regular) & 1.171 & $18.870 .000^{*}$ & $3.211 .9-5.4$ \\
\hline
\end{tabular}




\section{DISCUSSION:}

This study reports the frequency and risk indicators of periodontitis among the patients reporting to Islamabad Medical and Dental College (dental section). Of all patients, 471 $(42.9 \%)$ were diagnosed with periodontitis. As previously mentioned, the data in the present study included systemically healthy patients only, $42.9 \%$ of systemically healthy patients suffering from irreversible disease like periodontitis is a situation to be encountered and controlled before it gets worse. Similar prevalence was reported in dental institutes of Rawalpindi and Multan with $34.5 \%$ and $48.49 \%$ patients respectively. ${ }^{5,16}$ On the contrary, prevalence of periodontitis reported by Haq MW, in patients having systemic illness was higher (92\%) as compared to the present results. ${ }^{17}$ However, above mentioned researches included unhealthy individuals and smokers as well, which have masked the presence of periodontitis in systemically healthy patients, thus obscuring the importance of prevention of periodontitis in healthy individuals.

In regression analysis (table 3), the strongest predictor of periodontitis was found to be brushing habits with odd's ratio $3.37(C . I=2.19-5.17)$. This prediction indicates patient's brushing their teeth regularly (once daily) have 3.37 times greater odds of being safe from periodontitis than those who do not brush regularly. Although this is an established fact in general population, but since the population chosen in this research was systemically healthy, non-tobacco using individuals therefore, the importance of regular brushing habits should be reinforced in this population as well, as it has been in diabetics, obese and tobacco users. ${ }^{17}$ Furthermore, patients brushing their teeth irregularly (occasionally) had similar odds of being safe from periodontitis than those who do not brush their teeth at all $(\mathrm{OR}=0.95$, C.I. $=0.52-1.72$ ). Therefore, counselling/oral hygiene education to brush teeth regularly should be delivered to every individual (whether systemically healthy or unhealthy) for the betterment of oral hygiene ${ }^{18}$ so that overall incidence and prevalence of periodontitis can be controlled. This result is also consistent with another study from Rawalpindi reports a significant correlation of regular brushing habits with better periodontal health on applying chi-square but in their stepwise regression analysis only age, occupation and smoking are significantly related to periodontitis. ${ }^{5}$ This indicates how the effect of brushing habits was masked in regression analysis due to the presence of other strong variables and odd's ratio could not be calculated. A meta-analysis reported $34 \%$ lower odds of periodontitis in patients brushing regularly supporting the aforementioned results. ${ }^{19}$ Most of studies chosen in this 
meta-analysis were also on the general population therefore the exact odd's ratio for systemically healthy patients is difficult to analyze.

The second strongest association was of patients who visit dentists regularly which showed 3.21 times greater odds (C.I.=1.9-5.4) of being safe from periodontitis than those who never visited before (table 3). International researchers from Sweden in a 30-year outcome of preventive dental care highlighted the importance of regularity of dental visits in association with periodontal disease and caries. ${ }^{20} \mathrm{~A}$ meta-analysis reported that subjects who regularly visited dentists at least once a year had $44 \%$ lower risk of periodontitis than those who did not. ${ }^{19}$ Also researches from New York and North Jordan are in agreement with current findings. ${ }^{9,10}$ All the references given in this context are on general population and none of them is done exclusively on systemically healthy individuals. Furthermore, insignificant difference was seen in patients visiting irregularly and those who never visited before having $(\mathrm{OR}=0.79, \mathrm{C} . \mathrm{I}=0.60-1.04)$. The main reason behind this result was the irregular visitor are the patients who usually report to a dentist only when they have some severe dental issues like carious teeth, bleeding gums, pain, etc. As reported by Aliudddin AM et al. Pakistani population is reluctant to visit dentists due to multiple reasons and it is a common thought in the patients to report to the dentist only if they have severe dental problem (falling into the category of irregular visitors) ${ }^{21}$, therefore their odds of being safe from periodontitis is similar to those who never visited thus highlighting the importance of regularity of dental visits. In Pakistan, it has been noticed that minimal amount of patients shows up for regular dental visits ${ }^{21}$, most of which have underlying systemic disease due to which they are more concern about dental hygiene. ${ }^{22}$ Referring to results of current research this routine should be changed by educating the healthy and non-smoking individuals about the importance of regular dental checkups as well as educating them about their predilection towards periodontitis on ignorance and also educating them about the consequences of periodontitis. Age was also significantly associated with periodontitis (table 3 ) indicating that individuals < 50 years old have 2.9 times greater odds of being safe from periodontitis than $\geq 50$ years of age $(C . I=1.9-4.3)$. Although the association between periodontitis and age is also wellestablished fact ${ }^{3-5}$ but in most of the researches it has been studied without excluding the other systemic conditions. Elderly population is more prone to infections and diseases due to the adverse effects of aging on adaptive as well as innate immune response ${ }^{23}$, thus leading to chronic diseases. Direct relation of aging on periodontal loss as well as indirect effect through chronic systemic conditions indicates equal importance of education and 
awareness of systemically un healthy as well as systemically healthy elderly population for the prevention of periodontitis. Since aging cannot be modified but educating individuals beforehand about their periodontal health regardless of systemic health is an essential requirement to control this irreversible disease in the upcoming era.

Regression analysis also showed 1.5 times greater odds of being safe from periodontitis $(C . I=1.15-2.06)$ in patients with $\geq 12$ years of education (table 3$)$. This significant result is in contrast with the results reported from Multan, where an insignificant relation was reported between education status and dental disease ${ }^{16}$ This difference can be due to the inclusion of cofounders like smoking and systemic diseases which might have masked the significance of education in the results of the respective study. However, according to a study conducted in North Jordan, there is 5.5 times greater chance of periodontitis in patients with low education level. ${ }^{9}$ There was 5.5 times more chance of having periodontitis in patients with low education level which supports the results of present study. Higher prevalence of periodontitis among subjects with low education has also been reported in several other international studies. ${ }^{8,12,24}$ Although levels of education cannot be modified in majority, however, the thoughts of uneducated patients can be modified by counselling them through educational and awareness programs which emphasize on oral hygiene care. ${ }^{18}$ Periodontitis predilection was seen in male in cross-tabulation which has also been reported in earlier reseach ${ }^{19}$, however gender association was not seen in regression analysis indicating equal chances of females and males to suffer from periodontitis $(\mathrm{OR}=0.74$, C.I. $=0.56-0.96)$.

It should be noted that because this study was conducted on a group of patients referred to a periodontal department for treatment, the results are not likely to reflect the characteristics of whole population. Further large-scale, community-based studies on general population are required to determine the true prevalence of periodontitis in systemically healthy individuals in Pakistan.

\section{CONCLUSION:}

Systemically healthy patients of age $<50$ with regular brushing habits, having regular dental visits and well educated had more chance of being safe from periodontitis as compared to those systemically healthy patients who were $\geq 50$ years of age with the irregular or no brushing, irregular dental visits and education $\leq 12$ years. 
These risk indicators can help in prediction of periodontitis in systemically healthy patients reporting to clinics with lower education status, irregular brushing habits, irregular dental visits.

\section{Recommendations:}

Frequently, diabetics or smoker patients are more stressed upon for regular dental visits and a good oral hygiene as they are considered at high risk for periodontitis. This study shows periodontitis is also prevalent in healthy patients $(42.9 \%)$ thus highlighting the importance of routine dental examination, education of patient and regular brushing habits.

On the basis of the risk indicators identified in the present study and high prevalence of Periodontitis, it is high time that community health programs in Pakistan should be modified and innovative techniques should be employed to maximize the dental awareness of general population and increase the frequency of timely dental visits.

\section{REFERENCES:}

1. Guerra F, Mazur M, Ndokaj A, Corridore D, La Torre G et al. Periodontitis and the microbiome: a systematic review and meta-analysis. Minerva stomatol. 2018;67(6):250-8.

2. Natto ZS, Abu Ahmad RH, Alsharif LT, Alrowithi HF, Alsini DA et al. Chronic Periodontitis Case Definitions and Confounders in Periodontal Research: A Systematic Assessment. Biomed Res Int. 2018;Article ID 4578782:1-9.

3. Eke PI, Wei L, Borgnakke WS, Thornton-Evans G, Zhang $X$ et al. Periodontitis prevalence in adults $\geq 65$ years of age, in the USA. Periodontol 2000. 2016;72(1):7695.

4. Marcenes W, Kassebaum NJ, Bernabé E, Flaxman A, Naghavi M et al. Global burden of oral conditions in 1990-2010: a systematic analysis. J Dent Res. 2013;92(7):592-7.

5. Bokhari SA, Suhail AM, Malik AR, Imran MF. Periodontal disease status and associated risk factors in patients attending a Dental Teaching Hospital in Rawalpindi, Pakistan. J Indian Soc Periodontol, 2015;19(6):678-85

6. Van Dyke TE, Dave S. Risk factors for periodontitis J Int Acad Periodontol. 2005;7(1):3-7.

7. Wehmeyer MM, Corwin CL, Guthmiller JM, Lee JY. The impact of oral health literacy on periodontal health status. J Public Health Dent. 2014;74(1):80-7. 
8. Torrungruang K, Tamsailom S, Rojanasomsith K, Sutdhibhisal S, Nisapakultorn K et al. Risk indicators of periodontal disease in older Thai adults. J Periodontol. 2005;76(4):558-65.

9. Ababneh KT, Hwaij ZM, Khader YS. Prevalence and risk indicators of gingivitis and periodontitis in a Multi-Centre study in North Jordan: a cross sectional study. BMC Oral Health. 2012;12(1):1-8.

10. Oliveira Costa F, Miranda Cota LO, Pereira Lages EJ, Medeiros Lorentz TC, Soares Dutra Oliveira AM et al. Progression of periodontitis in a sample of regular and irregular compliers under maintenance therapy: a 3-year follow-up study. J Periodontol. 2011;82(9):1279-87.

11. Tonetti MS, Greenwell H, Kornman KS. Staging and grading of periodontitis: Framework and proposal of a new classification and case definition. J Periodontol. 2018;89(S1):149-61.

12. Eke PI, Dye BA, Wei L, Slade GD, Thornton-Evans GO et al. Update on prevalence of periodontitis in adults in the United States: NHANES 2009 to 2012. J Periodontol. 2015;86(5):611-22.

13. Lang NP, Cumming BR, Löe $\mathrm{H}$. Toothbrushing frequency as it relates to plaque development and gingival health. J Periodontol. 1973;44(7):396-405.

14. Yoshino K, Ito K, Kuroda M, Sugihara N. Tooth loss in problem-oriented, irregular, and regular attenders at dental offices. Bull Tokyo Dent Coll. 2016;57(1):11-9.

15. Fenlon C, O'Grady L, Doherty ML, Dunnion J. A discussion of calibration techniques for evaluating binary and categorical predictive models. Prev Vet Med. 2018;149(1):107-14.

16. Amin M, Amanullah BM, Tarar AM. Dental Caries, Periodontal Disease and their associated factors among patients visiting dental teaching hospital in Multan, Pakistan. J Pak Dent Assoc. 2016;25(3):99-102.

17. Haq MW, Tanwir F, Tabassum S, Nawaz M, Siddiqui MF. Association of periodontitis and systemic diseases. Int J Dent Oral Health. 2015;1(1):1-7.

18. Wu L, Gao X, Lo EC, Ho SM, McGrath C et al. Motivational interviewing to promote oral health in adolescents. J Adolesc Health. 2017;61(3):378-84.

19. Lertpimonchai A, Rattanasiri S, Arj-Ong Vallibhakara S, Attia J, Thakkinstian A. The association between oral hygiene and periodontitis: a systematic review and meta-analysis. Int Dent J. 2017;67(6):332-43. 
20. Axelsson $P$, Nyström B, Lindhe J. The long-term effect of a plaque control program on tooth mortality, caries and periodontal disease in adults: results after 30 years of maintenance. J Clinic Periodontol. 2004;31(9):749-57

21. Aliuddin AM, Ali JZ, Sheikh A, Rashid S. Obstacles to utilization of dental services in Karachi, Pakistan. Pak Armed Forces Med J. 2021;71(2):454-9.

22. Bangash RY, Khan AU, Manzoor MA. Diabetic patients; level of awareness about oral health knowledge, attitude and practices. Pak Oral Dent J. 2011;31(2)292-6.

23. Ebersole JL, Graves CL, Gonzalez OA, Dawson III D, Morford LA et al. Aging, inflammation, immunity and periodontal disease. Periodontol 2000. 2016;72(1):5475.

24. Borrell LN, Burt BA, Warren RC, Neighbors HW. The role of individual and neighborhood social factors on periodontitis: the third National Health and Nutrition Examination Survey. J Periodontol. 2006;77(3):444-53.

\section{FIGURES AND TABLES:}

Figure 1: Flow chat of patient selection

Table 1: Demographic data and dental care pattern of patients

Table 2: Classification table after inclusion of predictors

Table 3: Forward stepwise binary logistics regression analysis using periodontitis as dependent variable 


\section{Figures}

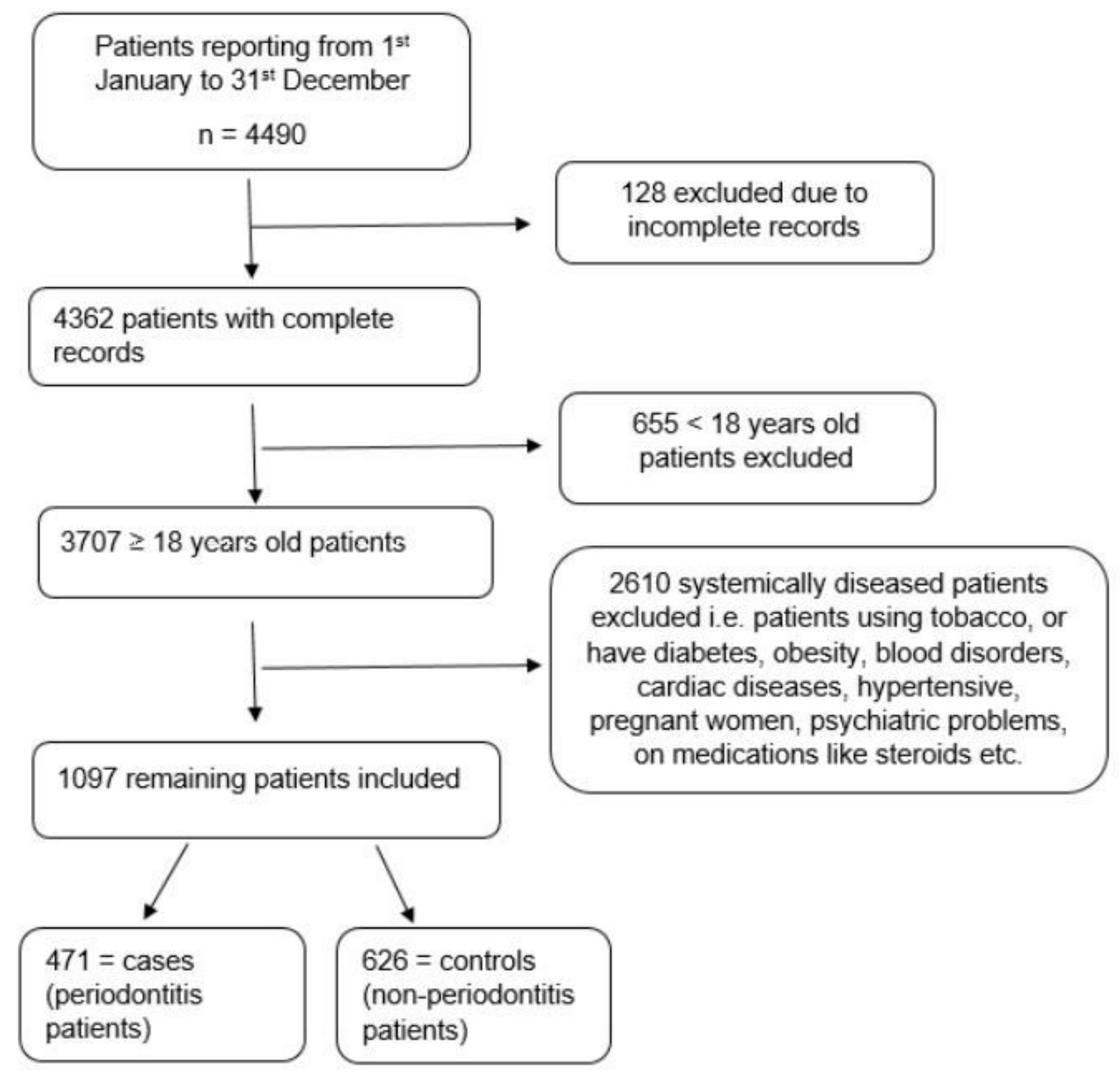

Figure 1

Flow chart of patient selection 